\title{
CONTAMINATION OF SOIL WITH TOXOCARA AND OTHER HELMINTHS IN SOILS OF AMADYIA DISTRICT, DUHOK GOVERNORATE, KURDISTAN REGION - IRAQ
}

\author{
GOLEK, H. I. ${ }^{1}-$ AL-SAEED, A. T. M. ${ }^{2 *}$ \\ ${ }^{I}$ Department of Microbiology, Medical Technical Institute, Polytechnic University, Duhok, Kurdistan \\ Region, Iraq \\ (phone: +964-750-767-6474) \\ ${ }^{2}$ Department of Microbiology, College of Medicine, University of Duhok, Kurdistan Region, Iraq \\ *Corresponding author \\ e-mail: adelalsaeed@uod.ac; phone: +964-750-450-1898 \\ (Received $18^{\text {th }}$ Jun 2019; accepted $16^{\text {th }}$ Oct 2019)
}

\begin{abstract}
In Amadyia District, Duhok Governorate, Kurdistan Region of Iraq, where there is a high population of people, domestic and stray animals, in addition to the presence of vegetation, grasses and large numbers of pastures. This study was conducted to determine of the soil's contamination with ova of Toxocara and other helminths in different areas of Amadyia district. A total of 700 soil samples were collected from different places such as public parks, private gardens, dog shelters, near pastures, parks of schools and around a slaughter house. The soil samples were examined using saturated zinc sulphate with specific gravity 1.2. Helminth ova were found in $593(84.71 \%)$ of the examined soil samples. Ova of Taenia were the most frequent helminths and found in 117 (16.71\%), followed by ova of Hymenolepis nana in 107 (15.28\%), Toxocara ova in 106 (15.14\%), Ancylostoma ova in 95 (13.57\%), Ascaris ova in $71(10.14 \%)$, Hymenolepis diminuta ova in 51 (7.28\%), and Trichuris ova in $46(6.57 \%)$. It is concluded that soils in areas of Amadyia district is contaminated with different helminths. The contamination of soil with Toxocara and other helminth ova is relatively high, the population are at a high risk to acquire infection through contact with environment and soil.
\end{abstract}

Keywords: environmental contamination, ova, zoonosis, zinc sulphate, Duhok, Iraq

\section{Introduction}

Humans acquire helminth infection by accidental swallowing of infective stages of parasites contaminating the soil (Blaszkowska et al., 2013; Cassenote et al., 2011). Humans are at the highest risk of infection because of outdoor activities and contact with contaminated soils (Al-Megrin, 2010). The poor sanitary condition in developing countries including Iraq leads to the presence of infective stages of parasites in the soils (Mahdi and Ali, 1993). Most often human become infected with helminths by contact with soil, water or food and grasses that contaminated either with ova or other stages of these parasites (Motazeddian et al., 2006; Sadjjadi et al., 2000). Infection rate in certain part of the world is related to poor environmental hygiene such as lack of clean water supply, contamination of the environment by human and animal wastes and bad habits (Anh et al., 2007).

A number of studies in the world have demonstrated the presence of pathogenic parasite in contaminated drinking water (Sprenger et al., 2014), soil (Tavalla et al., 2012), air (Ahmed, 2006) and socio-cultural, such as contact with animals (Thomas and Jeyathilakan, 2014), and lack of public education (Zibaei et al., 2010). In Northern Iraq (Erbil Province), the prevalence of parasitic infections among school aged children have been found to be high (Faraj, 2000). The awareness on the risk of contamination soil is still low (De-Moura et al., 2013). 
The parasites that cause helminth infections are naturally present in the environment, most often human and animals become infected with helminths by coming in contact with soil, water or food that contains the ova or other stages of these parasites (Soulsby, 1986).

Humans, particularly children are at the highest risk of infection because of their outdoor activities and playing on soils contaminated with animal feces.

The current study aimed to analyze soil samples collected in Amadyia district, Duhok Governorate, Kurdistan Region, Iraq, to determine their rate of infection by Toxocara and other helminth ova using saturated zinc sulphate, in order to conclude the infection risk of the local populace.

\section{Materials and methods}

Amadyia district (Fig. 1) is located in the North of Duhok Governorate - Kurdistan Region of Iraq. The city is situated 4,600 feet $(1,400 \mathrm{~m})$ above sea level. Total of human population 11,000. Climate of Amadyia has a hot-summer Mediterranean climate with long, hot summers and cool, wet winters. A total of 700 soil samples were collected from different locations of Amadyia district during the period of the year 2016-2017.

The soil samples were collected from different places of Amadyia district such as private gardens, dogs shelters, public park, parks of schools, near pasture and around slaughter house. During soil samples collection, many children were seen playing in the soil with their hands and not wearing shoes, in addition to that presence of dogs and their puppies around them (Fig. 2). The soil samples were collected in plastic bags and examined with some modification according to method of Mandarino-Pereira et al. (2010) and Zibaei et al. (2010). Amount ranging 25-50 g of soil from a depth of $3 \mathrm{~cm}$ ground was collected from each place and grinded, dissolved in normal saline, mixed well and filtered by sieving method, then centrifuged in $2000 \mathrm{rpm}$ for $5 \mathrm{~min}$. The supernatant was discarded and the sediment was re-suspended in normal saline. Then, centrifuged again and the supernatant was discarded and saturated zinc sulphate with specific gravity 1.2 was added to the sediment in a test tube and centrifuged in $1500 \mathrm{rpm}$ for $15 \mathrm{~min}$, then few drops of saturated zinc sulphate was added to filling the top of the test tube.

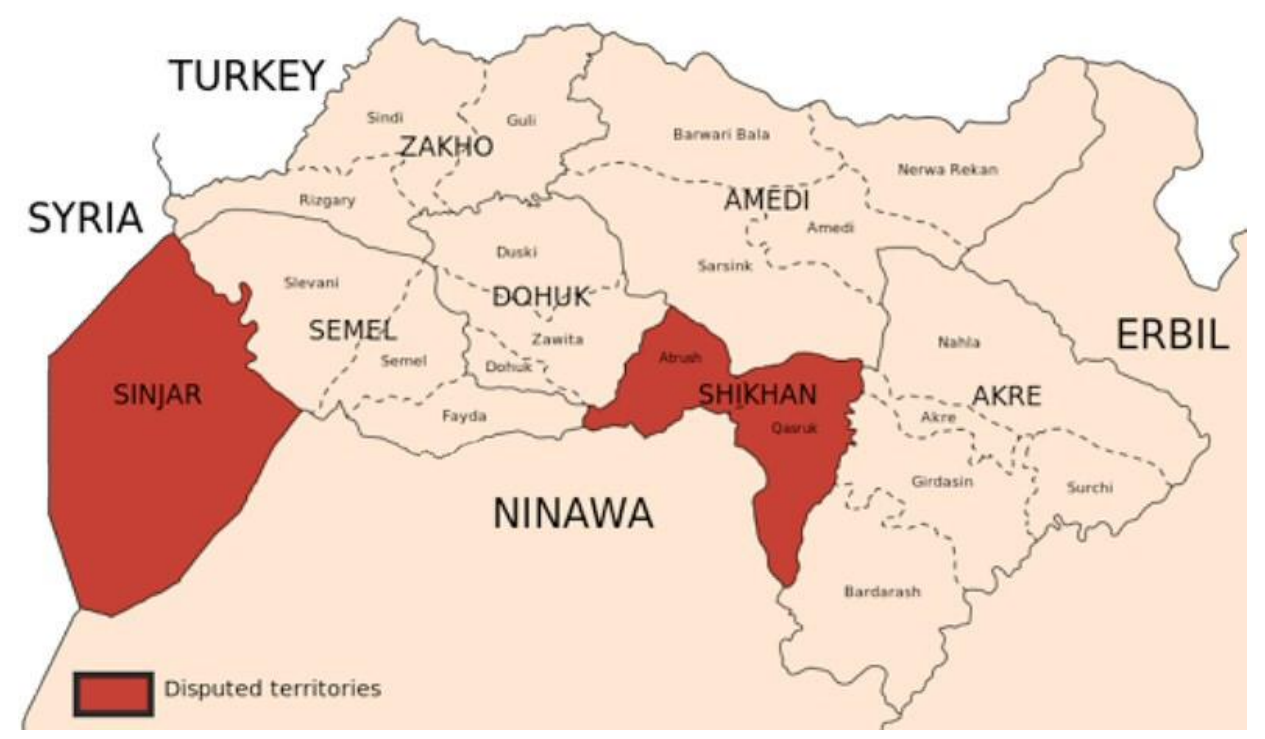

Figure 1. Map of Duhok Governorate showing Amadyia (Amedi) District 


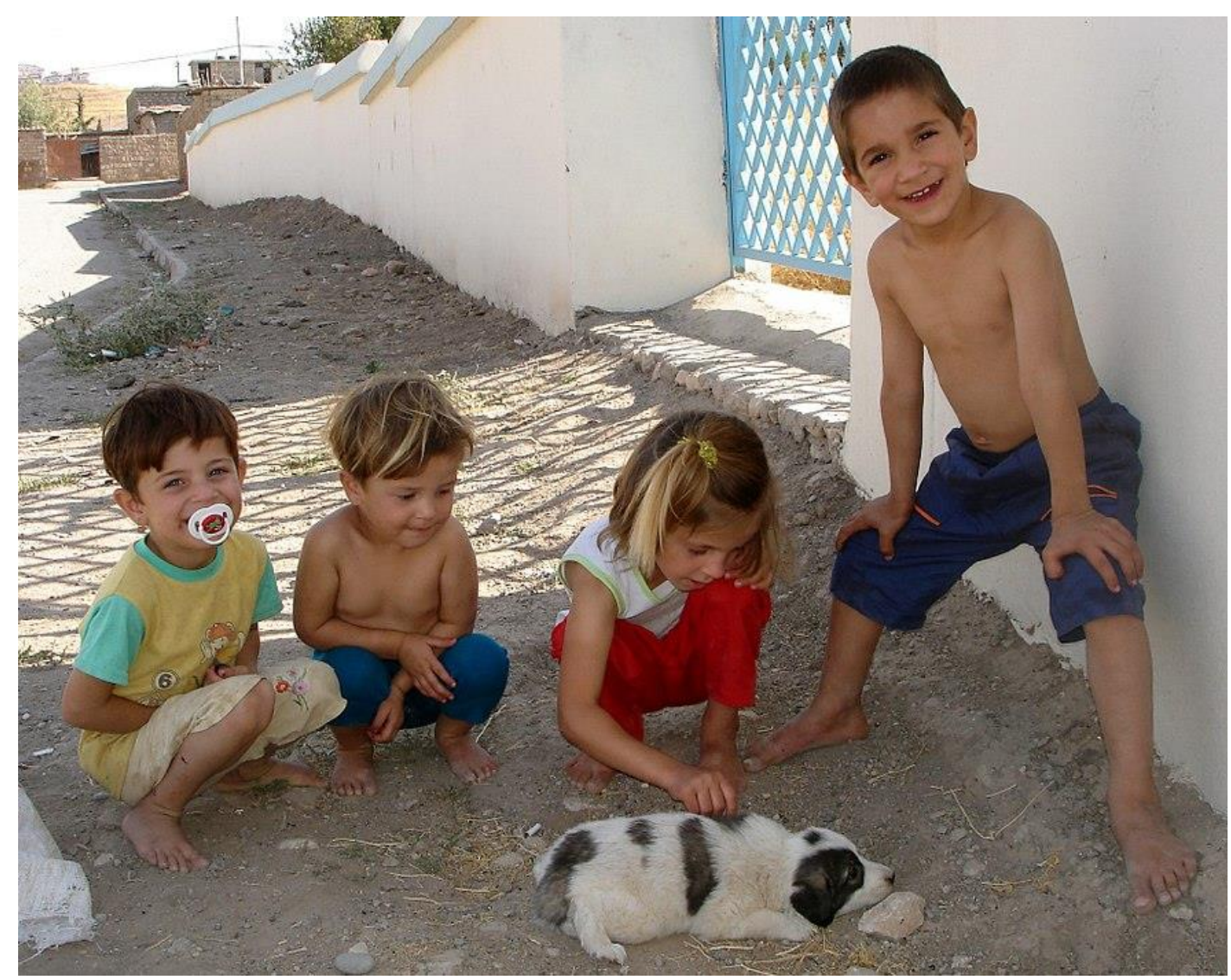

Figure 2. Children playing in the soil and puppy with hands and not wearing shoes (famous in rural areas of Kurdistan Region)

The cover slip was placed on the upper surface of tube in touch with the solution and was kept in the rack for $45 \mathrm{~min}$, then the coverslip was removed gently in a horizontal position and placed on a glass slide, examined under the light microscope. The ova of parasites were diagnosed according to their morphological features (Soulsby, 1986). The limitations of the current study are not studied the mean number of ova and the association between infection rate and, type of soils, $\mathrm{pH}$ of soils and habitats. Analysis of data was carried out using the Chi Square test and Statistical Package for Social Science (SPSS).

\section{Results}

Out of 700 soil samples examined, helminth ova were found in 593 (84.71\%). Taenia eggs $117(16.71 \%)$ were the most frequent helminth, followed by Hymenolepis nana ova in 107 (15.28\%), Toxocara ova in 106 (15.14\%), Ancylostoma ova in 95 (13.57\%), Ascaris ova in 71 (10.14\%), Hymenolepis diminuta ova in 51 (7.28\%), and Trichuris ova in $46(6.57 \%)$ as shown in Table 1.

It was clear from Table 2, that the ova of Taenia were positive in 17/130 (13.07\%) samples of soil obtained from dogs shelters, 20/127 (15.74\%) in private gardens, 25/106 $(23.58 \%)$ in parks of schools, 15/165 (9.09\%) near pastures, 29/64 (45.31\%) around slaughter houses and 11/108 $(10.18 \%)$ in public parks. There were statistically non significant $(\mathrm{p}=0.033)$ when compared with other helminths. 
Table 1. Contamination of soil samples with helminth ova in Amadyia District $(n=700)$

\begin{tabular}{c|c|c}
\hline Ova of parasites & Number of contaminated soil samples & Percentage \\
\hline Taenia & 117 & 16.71 \\
Hymenolepis nana & 107 & 15.28 \\
Toxocara & 106 & 15.14 \\
Ancylostoma & 95 & 13.57 \\
Ascaris & 71 & 10.14 \\
Hymenolepis diminuta & 51 & 7.28 \\
Trichuris & 46 & 6.57 \\
Total & 593 & 84.71 \\
\hline
\end{tabular}

Table 2. Contamination of soil samples with helminth ova in according to different places in Amadyia District $(n=700)$

\begin{tabular}{c|c|c|c|c|c|c|c}
\hline \multirow{2}{*}{$\begin{array}{c}\text { Place and no. of } \\
\text { examined soil samples }\end{array}$} & \multicolumn{7}{|c}{ Number of contaminated soil samples and percentage } \\
\cline { 2 - 8 } & Ta. & Hn. & To. & An. & As. & Hd. & Tr. \\
\hline Dogs shelters & 17 & 5 & 30 & 13 & 4 & 1 & 2 \\
$(130)$ & $(13.07)$ & $(3.84)$ & $(23.07)$ & $(10.0)$ & $(3.07)$ & $(0.76)$ & $(1.53)$ \\
\hline Private gardens & 20 & 16 & 13 & 15 & 15 & 10 & 8 \\
$(127)$ & $(15.74)$ & $(12.59)$ & $(10.23)$ & $(11.81)$ & $(11.81)$ & $(7.87)$ & $(6.29)$ \\
\hline Parks of schools & 25 & 34 & 15 & 28 & 21 & 15 & 21 \\
$(106)$ & $(23.58)$ & $(32.07)$ & $(14.15)$ & $(26.41)$ & $(19.81)$ & $(14.15)$ & $(19.81)$ \\
\hline Near pastures & 15 & 20 & 28 & 7 & 11 & 15 & 3 \\
$(165)$ & $(9.09)$ & $(12.12)$ & $(16.96)$ & $(4.24)$ & $(6.66)$ & $(9.09)$ & $(1.81)$ \\
\hline Around slaughter houses & 29 & 2 & 9 & 12 & 15 & 3 & 5 \\
$(64)$ & $(45.31)$ & $(3.12)$ & $(14.06)$ & $(18.75)$ & $(23.43)$ & $(4.68)$ & $(7.81)$ \\
\hline Public park & 11 & 30 & 11 & 20 & 5 & 7 & 7 \\
$(108)$ & $(10.18)$ & $(27.77)$ & $(10.18)$ & $(18.51)$ & $(4.62)$ & $(6.48)$ & $(6.48)$ \\
\hline Total & 117 & 107 & 106 & 95 & 71 & 51 & 46 \\
$(700)$ & $(16.71)$ & $(15.28)$ & $(15.14)$ & $(13.57)$ & $(10.14)$ & $(7.28)$ & $(6.57)$ \\
\hline P value & 0.033 & 0.00 & 0.005 & 0.115 & 0.083 & 0.002 & 0.008 \\
$(\mathrm{p}<0.01)$ & NS. & HS. & S. & NS. & NS. & HS. & HS. \\
\hline
\end{tabular}

Ta (Taenia), Hn (Hymenolepis nana), To (Toxocara), An (Ancylostoma), As (Ascaris), Hd (Hymenoleis diminuta), $\operatorname{Tr}$ (Trichuris)

Ova of $H$. nana were positive in 5/130 (3.84\%) samples of soil examined from dogs shelters, 16/127 (12.59\%) in private gardens, 34/106 (22.07\%) in parks of schools, $20 / 165(12.12 \%)$ near pastures, 2/64 (3.12\%) around slaughter houses and 30/108 $(27.77 \%)$ in public parks. There were statistically highly significant differences $(\mathrm{p}=0.00)$ when compared with other helminths.

Toxocara ova were positive in 30/130 (23.07\%) samples of soil were collected from dogs shelters, $13 / 127(10.23 \%)$ in private gardens, $15 / 106(14.15 \%)$ in parks of schools, 28/165 (16.96\%) near pastures, 9/64 (14.06\%), around slaughter houses and 11/108 $(10.18 \%)$ in public parks. There were statistically highly significant differences $(\mathrm{p}=0.00)$ when compared with other helminths.

Regarding to Ancylostoma ova were positive in 13/130 (10.0\%) samples of soil were examined from dogs shelters, $15 / 127(11.81 \%)$ in private gardens, 28/106 (26.41\%) in 
parks of schools, 7/165 (4.24\%) near pastures, 12/64 (18.75\%) around slaughter houses and 20/108 (18.51\%) in public parks. There were statistically non - significant differences $(\mathrm{p}=0.115)$ when compared with other helminths.

Ascaris ova were positive in 4/130 (3.07\%) samples of soil were obtained from dogs shelters, $15 / 127(11.81 \%)$ in private gardens, $21 / 106(19.81 \%)$ in parks of schools, $11 / 165(6.66 \%)$ near pastures, 15/64 (23.43\%) around slaughter houses and 5/108 $(4.62 \%)$ in public parks. There were statistically non-significant differences $(p=0.083)$ when compared with other helminths.

The ova of $H$. diminuta were positive in $1 / 130(0.76 \%)$ samples of soil were collected from dogs shelters, 10/127 (7.87\%) in private gardens, 15/106 (14.15\%) in parks of schools, 15/165 (9.09\%) near pastures, 3/64 (4.68\%) around slaughter houses and $7 / 108(6.48 \%)$ in public parks. There were statistically highly significant differences $(\mathrm{p}=0.002)$ when compared with other helminths.

Trichuris ova were positive in 2/130 (1.53\%) samples of soil were collected from dogs shelters, $8 / 127(6.29 \%)$ in private gardens, $21 / 106(19.81 \%)$ in parks of schools, 3/165 (1.81\%) near pastures, 5/64 (7.81\%) around slaughter houses and 7/108 $(6.48 \%)$ in public parks. There were statistically highly significant differences $(p=0.008)$ when compared with other helminths.

\section{Discussion}

Out of 700 soil samples examined, 593 (84.7\%) were positive for different species of helminth ova. The present study revealed high levels of contamination of soil by parasites. These results concerning the contamination of soil are in agreement with studies in many cities worldwide which also showed that the soils are contaminated with ova of helminth parasites.

In the current study the distribution of Toxocara ova was $15.14 \%$, as $23.07 \%$ in dogs shelters, $16.96 \%$ near pastures, $14.15 \%$ in parks of schools, $14.06 \%$ around slaughter houses, $10.18 \%$ in public park and $10.23 \%$ in private gardens. These results agree with the results of Fathailah (1988) which found 16\% prevalence of Toxocara ova in vegetables collected from different markets in Baghdad city. A study of Molan and Faraj (1989) reported 13.6\% prevalence of Toxocara ova in Erbil city. A study of AlBarazanjey (1992) found 14\% the prevalence of Toxocara ova in Erbil city. In Basra Mahdi and Ali (1993) recorded contamination rate of soil with Toxocara ova was $12.2 \%$. A study of Hussein (1997) found $18.1 \%$ the prevalence of Toxocara ova in Erbil city. A study done by Faraj (2000) reported $16 \%$ the prevalence of Toxocara ova in Erbil city. A study of Ahmed (2006) found the prevalence of Toxocara ova in Erbil city was 13\%. In Alnassiriyah city center, southern Iraq, Al-Kassar (2009) found $16.43 \%$ prevalence of Toxocara ova in public places and children play grounds, A study of Saida and Khder (2014) found that the prevalence of Toxocara ova in Erbil city, 12.2\% in leafy vegetables. On the other hand, the result of the current study is lower than that observed by Woodruff (1981) in Mosul district Iraq that reported the prevalence of Toxocara ova 25\%. A study of Nooraldeen (2015) in Erbil city, Iraq found the prevalence of Toxocara ova 50\% in public squares and parks. In northern and central of Jordan Toxacara ova were found in $15.45 \%$ of soils collected from school playgrounds and public places (Abo-Shehada, 1989). A study done by Al-Megrin (2010) in Riyadh, Saudi Arabia reported 20\% prevalence of Toxocara ova in leafy vegetables. In Turkey, 
Ge and Ge (2000) reported that $8.25-60.9 \%$ of public parks was contaminated with Toxocara ova.

In Iran, Motazedian et al. (2006) reported that the contamination rate of public places in Shiraz, Iran was $6.3 \%$ with Toxocara ova. A study done by Tavassoli et al. (2008) reported that the contamination rate of public places with Toxocara ova $7.8 \%$ in Urmia, Iran. A study of Zibaei et al. (2010) reported soil contamination with Toxocara eggs was $22.2 \%$ in Khorram Abad, Iran. A study of Tavalla et al. (2012) found that $79.3 \%$ the rate of Toxocara ova in public place in Tehran. In Italy, Habluetzel et al. (2003) reported $24 \%$ prevalence of soil contamination with Toxocara ova. In Brazil, several studies were conducted, and the soil contamination rate with Toxocara ova was $22.4 \%$ (Mandarino-Pereira et al., 2010), 30.2\% (Cassenote et al., 2011) and 36\% (Sprenger et al., 2014). A study done by Bojar and Káapeü (2012) in Poland found that $18.6 \%$ was prevalence of Toxocara ova. Another studies conducted in Brazil by De -Moura et al. (2013) and Marchioro et al. (2013) recorded $44 \%$ and $78.6 \%$ were prevalence of Toxocara ova in soils respectively. In Slovakia, the prevalence of Toxocara ova was 79.2\% (Rudohradská et al., 2011). In Poland, Blaszkowska et al. (2013) reported that prevalence of Toxocara ova was10.6\%, while in Portugal 63.3\% (Otero et al., 2014). A study done in India, 12.84\% (Sudhakar et al., 2013), while Thomas and Jeyathilakan (2014) reported 4.75\%, in Philippines 32\% (Paller and de Chavez, 2014). In the present study, the rate of soil contamination with Toxocara ova was $15.1 \%$ and statistical analysis showed the presence of highly significant difference. The differences between the results of all those studies mentioned may be attributed to a wide range of factors, such as climatic conditions, the population of dogs, soil type, number and volume of samples tested, the season in which sampling was performed, the mode of storage of soil samples, and the methods used for examination. In the current study, the public schools included did not keep their areas enclosed and allowing dogs to enter the school grounds.

The presence of ova in the soil samples collected suggests the dogs living around the school may be infected with Toxocara ova. During sample collection, children were seen playing in the soil with their bare hands and not wearing shoes or slipper, thus increasing the risk of acquiring Toxocara infection. In the current study, parasite ova were identified in almost all places that were not fenced and also in dog shelters. Fenced places specially arranged for dogs recreation were free of helminth ova, this means that the animals which had received anthelmintic drugs. Moreover, in this places have access only dogs with their owners. The explanation is that although the place was initially arranged for recreation of dogs subsequently the fence was broken and the access of stray dogs was free, suggesting a potential route of contamination of places.

In the present study the rate of some other helminth ova was reported as $15.28 \%$ of Hymenolepis nana, 7.28\% Hymenolepis diminuta, 6.57\% Trichuris trichuria, $13.57 \%$ was prevalence of Ancylostoma, 16.71\% for Taenia and $10.14 \%$ for Ascaris. All these types of parasitic ova were recovered from soils in many studies. In Baghdad, Fathailah, (1988) reported the prevalence of ova of some helminths as $22 \%$ Ascaris, $26 \%$ Hymenolepis nana, 12.57\% Ancylostoma, 22\% Toxoplasma gondii, 14\% Hymenolepis diminuta. Also in Baghdad Guirges and Al-Mofti (2005) found the prevalence of ova of some helminth eggs as 20\% Hymenolepis nana, 25\% Ascaris, 21\%, Hymenolepis diminuta, $19 \%$ of Ancylostoma and 15\% Trichuris. In Erbil city, Saida and Nooraldeen (2014) reported the prevalence of ova of some helminths as follow as: ova of Echinococcus granulosus 22.4\%, Ascaris 18.3\%, Hymenolepis nana 10.2\%, 
Hymenolepis diminuta $4.0 \%$, Trichostrongylus $8.1 \%$, Enterobius vermicularis $4.0 \%$ and Dipylidium caninum $6.1 \%$, the cysts of each of Entamoeba histolytica $20.4 \%$, Entamoeba coli $22.4 \%$, Giardia $16.3 \%$ and oocyst of Toxoplasma gondii $18.3 \%$. A study done by Nooraldeen (2015) in Erbil city was found ova of Hymenolepis diminuta in $75 \%$, Ascaris in 33.3\%, Taenia in 25\%, Ancylostoma in $25 \%$ and $16.7 \%$ for Trichuris. A study of Anh et al. (2007) reported the prevalence of Ancylostoma 19\%, Ascaris spp 27\%, Hymenolepis nana 22\%, Hymenolepis diminuta 20\% Echinococcus granulosus $23 \%$, in Cambodia. It is not possible to make an accurate comparison between the results of all those studies because the recovery of parasitic ova from different localities was obviously vary depending on environmental conditions, soil types, choice of sampling sites, the number of animals defecating in the sampled area, recovery methods and the increased prevalence of some of those helminth eggs in soil might be due to using of the humans and animals waste for fertilizing the farms in some countries, which is widely used in Iraqi farms.

Contamination of soil may result from poor environmental sanitation specially the presence of large stray dogs population. The cause of that may be return to the preference of these places by stray dogs in addition to that this area was always humid and helminth ova can remain viable at least few months in humid soil. While prolonged exposure to the sun in poor vegetation and dry soil may cause quick disintegration of the eggs. Climate conditions and other factors (temperature, humidity and rain, soil $\mathrm{pH}$ and soil type) were important factors for viability and development of ova, therefore, the differences in climate conditions from place to place and from year to year in the same place may lead to differences in contamination rate of soil which recorded along the months of year in different places or even in the same place during different years. In Iraq climatic conditions such as mild temperature, humidity and rain for maintenance and dispersion may be found in winter and spring seasons therefore, highest contamination rate obtained during the months of these seasons.

Sometimes the number of helminth ova per soil sample was not enough to cause infection and there was a positive correlation between the intensity of ova in soil and the prevalence of infection.

\section{Conclusions}

This study has shown that there is high level of contamination of soil of different parts of Amadyia district with Toxocara and other helminth ova and that examination of soil samples can be used as a strategy to determine the level of contamination of soil with helminth ova. The present study concluded that more consideration is necessary to improve personal and food hygiene particularly in children to avoid transmitting the infective stages of parasites for human through contaminated soils.

It is important that a further study needed to determine the relationship between the infection rate of helminth ova, soil types, soil $\mathrm{pH}$ and seasonal climatic variation.

\section{REFERENCES}

[1] Abo-Shehada, M. N. (1989): Prevalence of Toxocara ova in some schools and public grounds in northern and central Jordan. - Annals Tropical Medicine \& Parasitology 83(1): 73-75. 
[2] Ahmed, Q. M. (2006): Prevalence of intestinal parasites among food handlers and primary school children in Erbil province with initial cultivation of E. histolytica. - MSc Thesis, Salahaddin University, Erbil.

[3] Al-Megrin, W. A. I. (2010): Prevalence intestinal parasites in leafy vegetables in Riyadh, Saudi Arabia. - International Journal of Tropical Medicine 5(2): 20-23.

[4] Al-Kassar, N. R. (2009): Prevalence of Toxocara species eggs in public places and childrens play grounds of Anassiriyah city. - Journal of Thiqar University 5(2).

[5] Al-Barazanjey, R. K. A. (1992): Epidemiological study of Giardia sp. in Arbil governorate. - MSc Thesis, Salahaddin University, Erbil.

[6] Anh, V. T., Tram, N. T., Klank, L. T., Cam, P. D., Dalsgaard, A. (2007): Faecal and protozoan parasite contamination of water spinach (Ipomoea aquatica) cultivated in urban wastewater in Phnom Penh, Cambodia. - Tropical Medicine \& International Health 12(2): 73-81.

[7] Blaszkowska, J., Wojcik, A., Kurnatowski, P., Szwabe, K. (2013): Geohelminth egg contamination of children's play areas in the city of Lodz (Poland). - Veterinary Parasitology 192(1-2): 228-233.

[8] Bojar, H., Káapeü, T. (2012): Contamination of soil with eggs of geohelminths in recreational areas in the Lublin region of Poland. - Annals of Agricultural Environmental Medicine 19(2): 267-270.

[9] Cassenote, A. J. F., Neto, J. M. P., Lima-Catelani, A. R. A., Ferreira, A. W. (2011): Soil contamination by eggs of soil-transmitted helminths with zoonotic potential in the town of Fernandópolis, State of São Paulo, Brazil, between 2007 and 2008. - Revista da Sociedade Brasiliera de Medicina Tropica 44(3): 371-374.

[10] De-Moura, M. Q., Jeske, S., Vieira, N. J., Corrêa, G. T., Berne, A. M. E., Villela, M. M. (2013): Frequency of geohelminths in public squares in Pelotas, RS, Brazil. - Revista Brasileira de Parasitologia Veterinari 22(1): 175-178.

[11] Fathailah, Z. I. (1988): The presence of human parasites in vegetables collected from different markets in Baghdad city. - MSc thesis. University of Baghdad.

[12] Faraj, A. M. (2000): Prevalence of intestinal parasites in some kindergartens in the center of Erbil Northern Iraq. - Journal of Dohuk University 3(1): 7-12.

[13] Ge, S., Ge, H. (2000): Prevalence of Toxocara spp. eggs in the soil of public parks in Ankara, Turkey. - Dtsch tierarztl Wschr (107):72-75.

[14] Guirges, Y., Al-Mofti, A. (2005): The presence of protozoal cysts and helminthic ova on vegetables collected from Baghdad markets. - Journal of Faculty of Medicine, University of Baghdad 47(1): 70-72.

[15] Habluetzel, A., Traldi, G., Ruggieri, S., Attili, A. R., Scuppa, P., Marchetti, R., Menghini, G., Esposito, F. (2003): An estimation of Toxocara canis prevalence in dogs environmental egg contamination and risk of human infection in the Marche region of Italy. - Veterinary Parasitology 113: 243-252.

[16] Hussein, M. M. S. (1997): Prevalence of intestinal parasites in children up to 6 years old in Erbil province, Iraq. - Zanco Special Issue 1: 59-65.

[17] Mahdi, N. K., Ali, H. A. (1993): Toxocara eggs in the soil of public places and school in Barsah, Iraq. - Annals of Tropical Medicine and Parasitology 87:201-205.

[18] Mandarino-Pereira, A., de Souza, F. S., Lopes, C. W., Pereira, M. J. (2010): Prevalence of parasites in soil and dog feces according to diagnostic tests. - Veterinary Parasitology 170: 176-181.

[19] Marchioro, A., Colli, C. M., Ferreira, C. E., Tiyo, R., Mattia, S., de Souza, W. F., Falavigna-Guilherme, A. L. (2013): Identification of public areas with potential toxocariasis transmission risk using geographical information. - Acta Parasitologica 58(3): 328-333.

[20] Molan, A. L., Faraj, A. M. (1989): Prevalence of intestinal parasites in school children in Arbil, northern Iraq. - Saudi Medical Journal 10(2): 107-110. 
[21] Motazedian, H., Mehrabani, D., Tabatabaee. S. H. R., Pakniat, A., Tavalali, M. (2006): Prevalence of helminth ova in soil samples from public places in Shiraz. - Eastern Mediterranean Health Journal 12(5): 562-565.

[22] Nooraldeen, K. (2015): Contamination of public squares and parks with parasites in Erbil city, Iraq. - Annals Agriculture Environmental Medicine 22(3):418-420.

[23] Otero, D., Nijsse, R., Gomes, L., Alho, A., Overgaauw, P., Hoek, D., Madeira de Carvalho, L. M. (2014): Prevalência de ovos de Toxocara spp., no solo de parques publicos da area da Grande Lisboa, Portgal - resultados preliminares. - Acta Parasitologica Portuguesa 20(1/2): 47-50 (in Portuguese).

[24] Paller, V. G. V., de Chavez, E. R. C. (2014): Toxocara (Nematoda: Ascaridida) and other soil-transmitted helminth eggs contaminating soils in selected urban and rural areas in the Philippines. - The Scientific World Journal. DOI: 10.1155/2014/386232.

[25] Rudohradská, P., Papajová, I., Juriš, P. (2011): Pets as a source of parasitic soil contamination in the settlements of marginalised groups of inhabitants. - Folia Veterinaria 55(1): 33-35.

[26] Sadjjadi, S. M., Khosravi, M. B., Mehrabani, D. C., Oryan, C. D. (2000): Seroprevalence of Toxocara infection in school children in Shiraz, southern Iran. - Journal of Tropical Pediatric 46(6): 327-330.

[27] Saida, L. A., Nooraldeen, K. (2014): Prevalence of parasitic stages in six leafy vegetables in markets of Erbil City, Kurdistan Region, Iraq. - Zanco Journal of Pure and Applied Sciences 26(2): 25-30.

[28] Soulsby, E. J. I. (1986): Examination of Faeces. - In: Soulsby, E. J. L. (ed.) Helminths, Arthropods and Protozoa of Domesticated Animals. 7th Ed. William Clones Limited, Beccles and London, pp. 137-145.

[29] Sudhakar, N. R., Samanta, S., Sahu, S., Raina, O. K., Gupta, S. C., Madhu, D. N., Kumar, A.(2013): Prevalence of Toxocara species eggs in soil samples of public health importance in and around Bareilly, Uttar Pradesh, India. - Veterinary World 6(2): 87-90.

[30] Sprenger, L. K., Green, K. T., Molento, M. B. (2014): Geohelminth contamination of public areas and epidemiological risk factors in Curitiba, Brazil. - Brazilian Journal of Veterinary Parasitology 23(1):69-73.

[31] Tavalla, M., Oormazdi, H., Akhlaghi, L., Razmjou, E., Moradi, Lakeh, M., Shojaee, S., Hadighi, R., Meamar, A. R. (2012): Prevalence of parasites in soil samples in Tehran public places. - African Journal of Biotechnology 11(20): 4575-4578.

[32] Tavassoli, M., Hadian, M., Charesaz, S., Javadi, S. (2008): Toxocara spp. eggs in public parks of Urmia city, west Azebaijan province Iran. - Iranian J Parasitology (3):24-29.

[33] Thomas, D., Jeyathilakan, N. (2014): Detection of Toxocara eggs in contaminated soil from various public places of Chennai City and detailed correlation with literature. Journal of Parasitic Diseases 38(2): 174-180.

[34] Woodruff, A. W., Salih, S. Y. D., De Savigny, Baya, E. Z., Shah, A. I.(1981): Toxocariasis in Sudan. - Annals Tropical Medicine Parasitology 75(5): 559-561.

[35] Zibaei, M., Abdollahpour, F., Birjandi, M., Firoozeh, F. (2010): Soil contamination with Toxocara spp. eggs in the public parks from three areas of Khorram Abad, Iran. - Nepal Medical College Journal 12(2): 63-65. 